A C T A C H E M ICA S C A N D I N A V I CA 8 (1955) $509-518$

\title{
Effect of Irradiation on Hemin Formation
}

\author{
R. BONNICHSEN and G. HEVESY
}

\begin{abstract}
Nobel Institute for Biochemistry and Institute of Organic Chemistry and Biochemistry, University of Stockholm, Sweden
\end{abstract}

\begin{abstract}
Irradiation with Röntgen rays was found to depress very appreciably the rate of extrusion of ${ }^{50} \mathrm{Fe}$ bound to $\beta_{1}$-globulin in the circulation of the rabbit, the depression being much more pronounced 2 days after irradiation than shortly after exposure. It is suggested that erythrocytes of the bone marrow which have not yet completed their hemoglobin content are radioresistant and continue to incorporate ${ }^{50} \mathrm{Fe}$ in the bone marrow of the irradiated animal. Correspondingly, the effect of exposure to radiation on the rate of extrusion of ${ }^{59} \mathrm{Fe}$ from the plasma gets strongly pronounced only after the lapse of several hours.

A radiation dose which reduces the incorporation of ${ }^{50} \mathrm{Fe}$ into the hemoglobin to $30 \%$ of that of controls does not diminish the rate of incorporation of ${ }^{59} \mathrm{Fe}$ into cytochrom $\mathrm{b}$ of the liver of guinea-pigs.

The rate of incorporation of ${ }^{59} \mathrm{Fe}$ into myoglobin of the muscles of guinea-pigs was found to be reduced in the exposed animals. The interpretation of this finding are discussed.
\end{abstract}

The

he study of iron metabolism can be approached in different ways, a very profitable one being the study of the fate of plasma iron. Iron utilized for hemoglobin formation has to pass the plasma, so iron coming from and going to the various organs in which it is present as a constituent of ferritin, hemosiderin, myoglobin, cytochrom, catalase or other compounds.

Flexner et al. ${ }^{1}$ injecting labelled ferric chloride into the circulation of guineapigs observed a rapid initial disappearance of the radioactive iron from the circulation followed by a slower process. They interpreted the first process to be due to the disappearance of inorganic iron, the second to iron bound to proteins. These early experiments brought thus already out the difference between the circulating "physiological" iron and the plasma foreign iron injected into the circulation. The physiological plasma iron is bound to the $\beta_{1}$-globuline of the plasma which amounts to $3 \%$ of the plasma proteins. This protein fraction, the transferrin, is identical with Cohn's fraction IV-7 as shown by Holmberg and Laurell ${ }^{9}$, by Laurell ${ }^{3}$ and others. That the albumine fraction of the plasma proteins does not fix iron was recently demonstrated by Wuhrmann and Jasinski ${ }^{4}$ by combining paper chromatographic

Acta Chem. Scand. 9 (1955) No. 3 
with radioactive measurements. Fram the spots of the paper diagram of the plasma proteins from a rabbit 10 minutes previously injected with labelled ferric chloride only that due to $\beta_{1}$-globulin was found to be radioactive.

How the turnover rate of the circulating plasma iron is influenced by interference with hemeoipoetic processes going on in the human and animal organism was investigated in numerous cases by John Lawrence and his colleagues and several others.

Being interested in the problem of radiation anemia we determined the rate of disappearance of labelled plasma globulin from the circulation of rabbits exposed to Röntgen rays and the incorporation of ${ }^{59} \mathrm{Fe}$ into the circulating hemoglobin and into marrow hemin of guinea-pigs and rabbits. The effect of irradiation on the incorporation of ${ }^{59} \mathrm{Fe}$ into the red corpuscles of the rabbit and of the rat was previously investigated by Huff, Henessy and their associates ${ }^{5,6}$.

In view of the marked effect of irradiation on the incorporation of ${ }^{50} \mathrm{Fe}$ into hemoglobin we wished to know if hemins formed in another milieu than the bone marrow are affected by irradiation as well. We investigated therefore the effect of exposure to radiation on the incorporation of ${ }^{59} \mathrm{Fe}$ into the iron containing enzymes of the liver and into cytochrome c and myoglobin of the muscles. In this note results obtained in the investigation of cytochrom $b$ (Strittmatter ${ }^{26}$ ) of the liver and that of myoglobin are communicated.

\section{EXPERIMENTAL}

In 21 experiments with guinea-pigs an aggregate number of 220 animals, weighing $450-700 \mathrm{~g}$, were injected intraperitoneally with $0.2-0.4 \mathrm{ml}$ of saline containing 2 to $7 \mu \mathrm{g}$ of with ${ }^{\circ} \mathrm{Fe}$ labelled iron of $1 / 2-1 / 4 \mu$ Curie activity. Half of the guinea-pigs was exposed to $\mathrm{X}$-rays (160 kV, $43 \mathrm{r}$ per min. for 10 to 33 minutes). Injection took place 15 to $300 \mathrm{~min}$. following exposure. No food was administered during the experiment.

The animals were killed 4 to $48 \mathrm{hrs}$ later, their livers homogenized in sucrose and fractionated as described by Hogbein and Schneider. Ferritin was extracted both from microsomes and from the supernatant, cytochrom b hemin from microsomes (Loftfield ?) and catalase from the supernatent. Total iron, cytochrom c and myoglobin iron were furthermore isolated from the muscles making use of the method of Theorell and Åkeson ${ }^{8}$.

Ferritin was precipitated from the supermatant by addition of half volume of ammoniumsulfate. The precipitate was taken up in water and repeatedly fractionated with ammoniumsulfate. The precipitate was then taken up in water, heated to $70^{\circ} \mathrm{C}$ for a fow minutes and centrifuged after cooling. The supernatant ferritin was found to contain 17 to $20 \%$ iron.

The microsomes were homogenized in water, the $\mathrm{pH}$ adjusted to 5 and centrifuged after the lapse of 30 minutes. The precipitite was once more homogenized and washed with water. All the microsome ferritin was found to be in the water phase. The insoluble particles contained the cytochrom $b$ and some proteinbound iron. The cytochrom $b$ hemin was extracted from this fraction with a mixture of acetone and HCl (10 ml $20 \%$ $\mathrm{HCl}$ in 1 liter of acetone). The acetone was evaporated in vacuo, the precipitated hemin washed with $1 N \mathrm{HCl}$ and dissolved in ether. The ether was evaporated and the hemin combusted with sulfuric acid and hydrogen peroxide. The determination of iron was carried out by a colorimetric method using the sulfosalicylic acid complex.

An aliquot of the solution was used for colorimetric determination of the iron content, to another aliquot iron chloride was added bringing its iron content up to $500 \mu \mathrm{g}$. The iron was precipitated as FeS and filtered through a perforated aluminium dish covered with filter paper as described by Agner et al. ${ }^{\circ}$. The aluminium dish was then placed under the window of a Geiger counter. An aliquot of the solution which was injected was trea- 
ted in the same way. The data obtained permitted to calculate the relative specific activity of the iron fraction (activity per $\mathrm{mg}$ iron in arbitrary units) and also the absolute specific activity (percentage of injected ${ }^{\circ \theta} \mathrm{Fe}$ present in $1 \mathrm{mg}$ of iron).

In our experiments on the iron turnover of the plasma $5-10 \mu \mathrm{g}$ of iron having an activity of about $2 \mu$ Curie were injected into the ear vein of a rabbit. After the lapse of about $1 \mathrm{~h} \mathrm{a}$ few $\mathrm{ml}$ of the plasma of this rabbit, which now contained all ${ }^{50} \mathrm{Fe}$ present in the plasma as $\beta_{1}$-globulin, was injected into the jugular vein of a sister rabbit. At intervals blood samples were taken from the carotic vein of this rabbit, the heparinized blood centrifuged, the plasma combusted as described above, $500 \mu \mathrm{g}$ carrier iron added and the iron precipitated as sulphide as described above. $2-3 \mathrm{~kg}$ rabbits were applied in these experiments, in which the effect of irradiation on the formation of labelled hemoglobin and labelled hemin of the bonemarrow was investigated.

\section{RESULTS}

\section{a) Cytoch rom b}

The data obtained for the ratio of the specific activities of cytochrom $b$ iron (Strittmatter ${ }^{26}$ ) and also of microsome ferritin iron of irradiated and control guinea-pigs are listed in Table 1. Out of 13 ratios listed in Table 1 one is as low as $\mathbf{0 . 7 7}$, but even this ratio is by about $250 \%$ higher than that obtained for hemoglobin iron, which was found to be 0.3 , corresponding to a depression of ${ }^{59} \mathrm{Fe}$ incorporation into hemoglobin in the irradiated guinea-pig to $1 / 3$ of that into the hemoglobin of controls.

Table 1. Effect of exposure to 500-1400 $\mathrm{r}$ on the incorporation of ${ }^{50} \mathrm{Fe}$ into the cytochrom $b$ of the liver of guinea-pigs. Each figure is obtained by pooling 5 livers.

Time between injection of ${ }^{59} \mathrm{Fe}$ Ratio of spec. activ. of Ratio of spec. activity of and removal of the liver in hrs cytochrome $b$ iron of microsome ferritin iron of irradiated and control irradiated and control animals animals

\begin{tabular}{rll}
\hline 4 & 2.52 & 1.62 \\
4 & 0.77 & 1.12 \\
4 & 0.96 & 1.05 \\
16 & 1.17 & 0.91 \\
17 & 1.48 & 1.35 \\
17 & 0.88 & 1.16 \\
17 & 0.92 & 1.06 \\
17 & 1.90 & 1.39 \\
17 & 1.15 & 1.40 \\
48 & 1.12 & 0.94 \\
48 & 1.16 & 1.19 \\
48 & 1.25 & 1.81 \\
48 & 0.94 & 2.13 \\
\hline Mean value & $1.25 \pm 0.036$ & $1.32 \pm 0.010$
\end{tabular}

Not only does exposure of guinea-pigs to large doses of Röntgen rays not diminish the rate of incorporation of the ${ }^{59} \mathrm{Fe}$ into cytochrome b but as seen in Table 1 promotes it. The increased incorporation of ${ }^{59} \mathrm{Fe}$ does, however, not or not mainly indicate an increased rate of formation of cytochrome $b$. It is, at least to a large extent, due to the change in sensitivity of the radio- 
agtive indicator. About half of the plasma iron takes its way into the bone marrow and is applied to hemoglobin synthesis, the other half into the liven and other organs. The labelled iron atoms which leave the plasma are replaced by inactive ones coming from the organ depots and to a minor extent from the intestine. Irradiation upsets this distribution. Incorporation into hemoglobin is strongly reduced which results in an increased life time of $\$ 9 \mathrm{Fe}$ in the plasma which in turn leads to a change in the sensitivity of the radioactive indicator. The increase in the iron content of the plasma of the irradiated animals (Schuck ${ }^{10}$, Ludewig ${ }^{11}$ ) remains behind the increase of its ${ }^{59} \mathrm{Fe}$ content and correspondingly the sensitivity of the radioactive indicator decreases. Thus we can expect more ${ }^{59} \mathrm{Fe}$ to reach the liver in the exposed animals than in the controls. If this line of thought is correct we must expect the ratio of the specific activity of the iron of exposed and control animals, which for cytochrom b was found to be 1.3, to be about 1.3 for other liver fractions as well (as far as their rate of formation is not influenced by irradiation). As seen from Table 1 this is almost the case for microsome ferritin, 1.32 being found for the corresponding ratio.

Elmlinger et al..$^{12}$ found in normal humans about $55 \%$ of the iron which passed the plasma to be utilized in red corpuscle formation. The rest takes its way: into the other organs. Should the last mentioned inflow be unilateral the iron content of these organs would increase already in the course of 120 days with about $2 \mathrm{~g}$ which is more than the total iron depot of a man which amounts to about $1.6 \mathrm{~g}$ (Haskins ${ }^{13}$ ). We have therefore to conclude that the flow or iron from the plasma into the depot organs goes hand in hand with an outflow of an even larger amount of iron from the depots into the plasma.

A different line of thought supports this view. Hemoglobin iron is almost quantitatively reutilized for hemoglobin formation as shown by Hahn et al. ${ }^{20}$. We injected labelled red corpuscles of a donor rabbit to an acceptor rabbit and after the short interval of only 5 hours found 90 times more ${ }^{59} \mathrm{Fe}$ in the liver than in the spleen of the thoroughly perfused animals, the gall containing $2 / 3$ of that of the last mentioned organ. The reutilization of this iron for hemoglobin formation necessitates its passage through the plasma to the marrow. Thus a continuous flow of iron from the liver (and presumably other organs responsible for the phagocytosis of red corpuscles) to plasma has to take place. In the course of 120 days (the time necessary to replace the circulating human red corpuscles) about $2 \mathrm{~g}$ of iron has to pass from the depot organs to the bone marrow. The corresponding figure in the rabbit in the course of 50 days is about 0.1 .

Effect of irradiation on ${ }^{59} \mathrm{Fe}$ incorporation into hemoglobin. As to be expected and also shown by Huff ${ }^{5}$, Hennessy ${ }^{6}$ and their associates irradiation strongly depresses the incorporation of ${ }^{59} \mathrm{Fe}$ into hemoglobin. Our results obtained with guinea-pigs injected within 6 hours after exposure and killed 17 hours later are seen in Table 2.

In each of the experiments Nos. 9 to 16 the blood of 10 guinea-pigs, in Nos. 21 and 22 of 20 animals was pooled.

Incorporation of ${ }^{59} \mathrm{Fe}$ into hemoglobin was thus reduced by irradiation in these experiments to $30 \%$ of that of controls. 
Table 2. Effect of irradiation with 500-1300 r onithe incorporation of ${ }^{59} \mathrm{Fe}$ into hemoglobin of guinea-pigs.

\begin{tabular}{|c|c|}
\hline Number of experiment & $\begin{array}{c}\text { Ratio of spec. activ. of } \\
\text { hemoglobin iron of irradiated } \\
\text { and control guinea-pigs }\end{array}$ \\
\hline 9 & \\
10 & 0.20 \\
12 & 0.17 \\
13 & 0.36 \\
14 & 0.72 \\
16 & 0.25 \\
21 & 0.21 \\
22 & 0.29 \\
& 0.24 \\
\hline
\end{tabular}

Mean value: $0.298 \pm 0.158$

Delay of the effect of irradiation on the incorporation of labelled iron into hemoglobin. Red corpuscles are very radioresistant. We need very massive doses to achieve hemolysis and a dose of $4000 \mathrm{r}$ for example as shown by Sheppard ${ }^{14}$ does not influence the rate of intrusion of ${ }^{42} \mathrm{~K}$ in the red corpuscle though it does to some extent weaken the mechanism responsible for the concentration of potassium in the red corpuscles. Dog blood exposed to a dose of $200000 \mathrm{r}$ does not hemolyse as observed by Nizet et al. ${ }^{24}$.

The radioresistance of circulating red corpuscles suggests that the not fully completed red corpuscles in the bone marrow are radiation resistant as well and continue even in the exposed animal to complete their hemoglobin content. In the bone marrow of swine exposed to radiation of the Bikini explosion often only fat cells and a few clumps of erythrocytes were found ${ }^{25}$.

The above conclusion is supported by the observation that the uptake of ${ }^{59} \mathrm{Fe}$ or ${ }^{14} \mathrm{C}$ by the hemoglobin of red corpuscles in vitro is not reduced by irradiating the animal before securing the blood sample. Reticulocytes and other types of incomplete red corpuscles can complete their hemoglobin content in vitro. Not only is the ${ }^{14} \mathrm{C}$ incorporation in vitro not smaller into the blood corpuscles of irradiated animals than into those of controls, it is even markedly enhanced as shown by Nizet et al. ${ }^{15}$ who investigated the uptake of ${ }^{14} \mathrm{C}$ by the dog. Rauntanan and one of us made similar observations when studying incorporation of ${ }^{59} \mathrm{Fe}$ in vitro into the red corpuscles of the hen which was found to be increased in extreme cases up to $300 \%$ if the hen was 18 hours previously exposed to a dose of $1000 \mathrm{r}$. Irradiation induces presumably the bone marrow to release some of the red corpuscles in an earlier stage of their maturation. Nizet et al. have furthermore shown that irradiation in vitro produces changes in the plasma which are favourable to ${ }^{59} \mathrm{Fe}$ incorporation into the red corpuscles.

These considerations support the conclusion that as far as red corpuscles in the advanced stage of their maturation are present in the bone marrow a completion of their hemoglobin content takes place even in the exposed organism

Acta Chem. Scand. 9 (1955) No. 3 


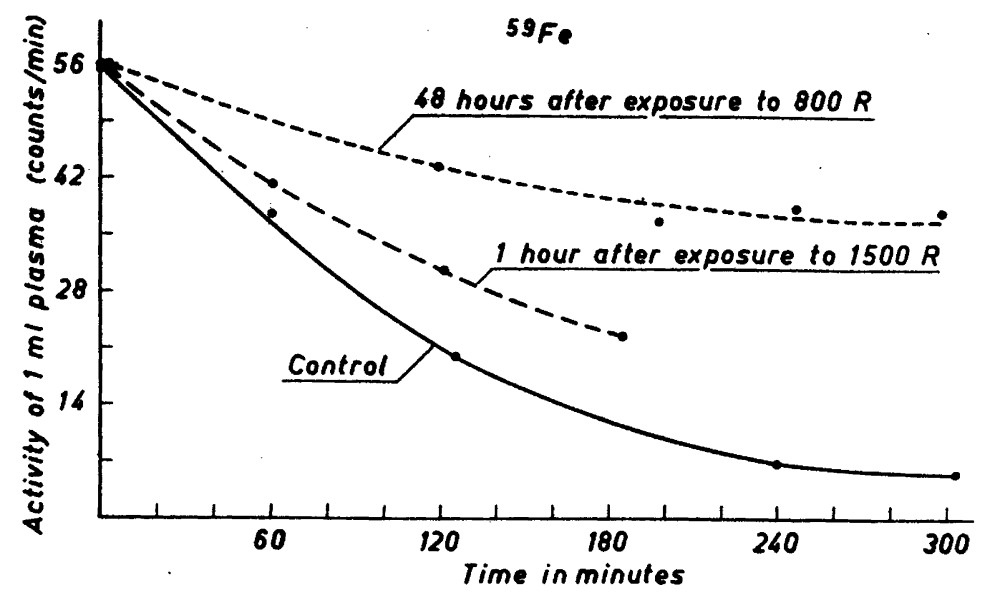

Fig. 1. Effects of exposure to Röntgen rays on the rate of extrusion of circulating labelled plasma iron from the circulation of rabbits.

and that some of the ${ }^{59} \mathrm{Fe}$ administered shortly after irradiation will be utilized by the bone marrow. With increasing time the completed red corpuscles being discharged into the circulation or wiped out in the exposed organism the utilization of ${ }^{59} \mathrm{Fe}$ by the bone marrow will diminish and after the lapse of about 1 day may almost cease. As the non-utilization of labelled plasma iron by the bone-marrow leads to a depressed turnover rate of the plasma iron this depression is to be expected not to be shown to its full extent already shortly after irradiation but only at a later date. That this is the case is demonstrated by Fig. 1 and the data of Table 2 .

As seen in Fig. 1 the effect of irradiation with such a high dose as $1700 \mathrm{r}$ influences the rate of extrusion of ${ }^{59} \mathrm{Fe}$ from the plasma, when measured $1 / 2$ hour only after exposure, is much less than an irradiation with $800 \mathrm{r}$ only, when the rate of extrusion is measured 2 days after irradiation.

When injecting rabbits weighing $600 \mathrm{~g}$ intraperitoneally with labelled $\mathrm{FeCl}_{3} 48$ hours after exposure to $500 \mathrm{r}$ we observed 5 hours after injection the ${ }^{50} \mathrm{Fe}$ content of the plasma to be $120 \%$ higher than that of the control. In experiments in which 500-900 g rabbits were injected intraperitoneally within 1/2 hour after irradiation with $5 \mu \mathrm{g}$ labelled iron as $\mathrm{FeCl}_{3}$ and killed 3 hours later the ${ }^{50} \mathrm{Fe}$ content of the plasma was increased with $6 \%$ only. Further data on the effect of time which elapsed after exposure to irradiation on the ${ }^{59} \mathrm{Fe}$ content of the plasma is seen from Table 3. This table also contains data on the incorporation of ${ }^{59} \mathrm{Fe}$ into hemoglobin, which is much more markedly depressed under the effect of irradiation after the lapse of 48 hours than after that of $1 / 2$ hour. In these experiments $5 \mu \mathrm{g}$ of iron as $\mathrm{FeCl}_{3}$ were interperitoneally injected to each rabbit. Similar observations on the effect of irradiation on the incorporation of ${ }^{59} \mathrm{Fe}$ into the red corpuscles were made by Hennessy and Huff ${ }^{6}$. 
These results support the conclusion arrived at that for some time after irradiation the completion of the hemoglobin content of the red corpuscles is still going on in the marrow and supports indirectly also the result arrived at by Thorell that hemoglobin is layed down in the later phase of the maturation of erythropoeitic cells of the bone marrow.

Table 3. Incorporation of interperitoneally injected ${ }^{59} \mathrm{Fe}$ in the course of 5 hours into the hemoglobin of controls and with $500 \mathrm{r}$ irradiated rabbits. $C=$ control. $R=$ exposed.

\begin{tabular}{|c|cc|cc|}
\hline \multirow{2}{*}{$\begin{array}{c}\text { Time in hours between } \\
\text { exposure and injecting } \\
\text { of }{ }^{50} \mathrm{Fe}\end{array}$} & \multicolumn{4}{|c|}{ Relative ${ }^{59} \mathrm{Fe}$ content } \\
\cline { 2 - 5 } & \multicolumn{2}{|c|}{ Plasma } & Hemoglobin \\
\hline & & $\mathrm{C}$ & $\mathrm{C}$ & $\mathrm{R}$ \\
& 100 & 100 & 100 & 100 \\
0 & 100 & 118 & 100 & 68 \\
0.5 & 100 & 124 & 100 & 56 \\
17 & 100 & 223 & 100 & 3.2 \\
48 & 100 & 447 & 100 & 17.3 \\
\hline $72 * *$ & &
\end{tabular}

* For the bone marrow hemin the corresponding figure was 43.

**. Data obtained by Huff et al. ${ }^{10}$

\section{b) Muscle myoglobin}

In view of the fact that the chemical composition of myoglobin closely resembles that of hemoglobin - they are differing only as to their degree of polymerisation - it was of great interest to investigate the effect of exposure to irradiation on the incorporation of ${ }^{59} \mathrm{Fe}$ into the myoglobin of guinea-pigs extracted from their muscles. The method of purification was that described by Theorell and Ákeson ${ }^{8}$. The myoglobin obtained was practically free from hemoglobin as revealed by a spectroscopic investigation of the CO-myoglobin. In 4 experiments in each of which 10 female guinea-pigs having a weight of $450-550 \mathrm{~g}$ were injected 6 hours after exposure to $1400 \mathrm{r}$ with $3 \mu \mathrm{g}$ of labelled iron as sodium iron citrate and killed 18 hours later and 10 controls were treated in the same way the following rel. specific activity figures were obtained for the myoglobin and hemoglobin iron of controls and exposed animals.

Table 4. Effect of irradiation on the incorporation of ${ }^{59} \mathrm{Fe}$ into myoglobin and hemoglobin of guinea-pigs. Control $=C$, exposed $=R$.

\begin{tabular}{|c|c|c|c|c|c|c|}
\hline $\begin{array}{l}\text { No. of } \\
\text { expt. }\end{array}$ & \multicolumn{2}{|c|}{$\begin{array}{l}\text { Rel. spec. activity * } \\
\text { of myoglobin }\end{array}$} & Ratio $\frac{\mathbf{C}}{\mathbf{R}}$ & \multicolumn{2}{|c|}{$\begin{array}{l}\text { Rel. spec. activity } \\
\text { of hemoglobin }\end{array}$} & Ratio $\frac{\mathbf{C}}{\mathbf{R}}$ \\
\hline $\begin{array}{l}1 \\
2 \\
3 \\
4\end{array}$ & $\begin{array}{c}C \\
0.098 \\
0.034 \\
0.476 \\
0.415\end{array}$ & $\begin{array}{c}R \\
0.042 \\
0.026 \\
0.215 \\
0.164\end{array}$ & $\begin{array}{l}2.3 \\
1.3 \\
2.2 \\
2.6\end{array}$ & $\begin{array}{l}\mathrm{C} \\
0.236 \\
\overline{2.19} \\
2.44\end{array}$ & $\begin{array}{l}R \\
0.047 \\
- \\
0.48 \\
0.68\end{array}$ & $\begin{array}{l}5.0 \\
\overline{4.6} \\
3.6\end{array}$ \\
\hline
\end{tabular}

* count per $\mu \mathrm{g} \mathrm{Fe}$.

Acta Chem. Scand. 9 (1955) No. 3 
Under effect of exposure the ${ }^{5 \mathrm{Fe}}$ incorporation into myoglobin was thus reduced to $1 / 2$, that into hemoglobin to $1 / 4$ of that of the controls. In the 2 last experiments we determined the effect of exposure on the specific activity of the total iron present in the muscles as well and found it, as to be expected (cf. p. 511), increased under the effect of exposure, in the third experiment from 0.714 to 0.810 , in the fourth one from 0.687 to 1.04 .

\section{DISCUSSION}

Hemoglobin is one of the comparatively few molecular constituents of the adult organism that is formed in close connection with cell division. The latter being very susceptible to the effect of ionising radiation, exposure to radiation is bound to interfere with hemoglobin formation as well. Furthermore marrow cells are radiosensitive and exposure to radiation may lead to destruction of marrow cells. Irradiation of rats with $400 \mathrm{r}$ was found to lead to a decrease in the total number of marrow cells to almost one half of its normal value in the course of the first day following exposure (Brecher ${ }^{15}$ ) and the chemical composition of the bone marrow was found markedly influenced. Lutwak-Mann ${ }^{17}$ found 3 hours only after total body exposure to a dose of $1500 \mathrm{r}$ the labile acid-soluble $\mathrm{P}$ of the bone marrow of rabbits to be reduced by $30 \%$, that of DNA and RNA phosphorus by 20 and $16 \%$. The total nucleic acid $P$ of the marrow of the to $500 \mathrm{r}$ exposed rat amounted to only half of that of controls. Mandel et al. ${ }^{18}$ report the bone-marrow of rats exposed to $500 \mathrm{r}$ to show after the lapse of 26 hours a by $50 \%$ reduced PNA content, the DNA being reduced to $30 \%$ of that of the controls after the lapse of 2 days. Thus radiation anemia is at least partly due to the fact that hemoglobin is formed in close connection with the cell division and also that it takes place in the radiosensitive marrow cells.

Altmann et al. (Richmond ${ }^{19}$, Stokinger ${ }^{20}$ ) in their very extended studies found incorporation of ${ }^{14} \mathrm{C}$ into globin and hemin to be influenced at a very different rate by irradiation. Incorporation of ${ }^{14} \mathrm{C}$ into hemin of the exposed animals was greatly depressed, whereas globin was affected to a considerably smaller extent. From this finding it does not necessarily follow that it is not the milieu of its formation, the bone marrow, which is responsible for the radiation sensitivity of the formation of hemoglobin.

We found no interference with the formation of cytochrom $b$ in the liver of the strongly irradiated guinea-pig. In this case heme formation is thus not radiosensitive. We found, however, interference with formation of myoglobin. We are reluctant to make any definite conclusion from this finding. The possibility must not be excluded that myoglobin formation in the muscles of the 450-550 g guinea-pig takes place in connection with mitotic processes. Histologic evidence proves cell division in muscle tissue to be a very rare process. A very few mitoses would however be sufficient to account for the formation of much of the myoglobin of the muscles as a process preceded by cell division. This is shown by the following calculation.

The maintenance of a hemoglobin level of $6 \mathrm{~g}$ per $\mathrm{kg}$ guinea-pig requires a mitotic figure of $1-2 \%$ in the hemopoietic bone marrow weighing about $10 \mathrm{~g}$. The amount of myoglobin present in the guinea pig is not known. Assuming 
the hemoglobin content of the guinea-pig to be 32 times its myoglobin content as found for the rat by Drabkin ${ }^{27}$ and furthermore that the muscle tissue of the guinea-pig amounts to $40 \%$ of its body weight, i.e. its myoglobin being formed in a 40 times larger amount of tissue than its hemoglobin, then the mitotic figure to maintain the production of myoglobin should be $32 \times 40$ times less than that permitting the production of hemoglobin. We have further to consider that the life cycle of myoglobin is longer than that of hemoglobin. No exact data are available on the life cycle of myoglobin. Theorell et at ${ }^{28}$ estimate hemoglobin to have an about 4 times longer life time than hemoglobin and from the finding of Helwig and Greenberg 21 a ratio of $2-3$ follows for the life time of the protohemin part of myoglobin and hemoglobin; our figures suggest a ratio of about 3 . We have thus to multiply the above mentioned $32 \times 40$ by at least 3 to arrive at the ratio of mitotic figures in the hemopietic bone marrow and the muscle tissue assuming the formation of myoglobin being preceded by cell division. This ratio works out to be about 4000 . If out of 200000 cells one would show division it would suffice to interpret myoglobin formation to be in close connection with cell division.

It is often assumed that amiotic division of muscle cells is less rare than a miotic one. As irradiation can be expected to interfere with this type of cell division as well it is bound to depress myoglobin formation if myoglobin is laid down as we are inclined to assume in the course of maturation of muscle cells. We are engaged in determining the effect of irradiation on the incorporation of ${ }^{59} \mathrm{Fe}$ into myoglobin of both fully grown and growing rats in the hope of getting more information on the radiation sensitivity of myoglobin formation.

Our thanks are due for valuable assistance to Mr. Åke Åkeson, Mrs. Ingegerd Björkman and Miss Jutta Schliack, to the Knut och Alice Wallenbergs Stiftelse and to the Riksföreningen för kräftsjukdomarnas bekämpande, Cancernämnden, for their generous support of this investigation.

\section{REFERENCES}

1. Flexner, L. B., Vosburgh, G. J. and Cowie, D. B. Am. J. Physiol. 153 (1948) 503.

2. Holmberg, C. G. and Laurell, C. B. Acta Physiol. Scand. 10 (1945) 307.

3. Laurell, C. B. Acta Physiol. Scand. 14, Suppl. 4 (1947) 1.

4. Wuhrmann, F. and Jasinski, B. Schweiz. med. Wochschr. 83 (1953) 1.

5. Huff, R. L., Bethard, W. F., Garcia, J. F., Roberto, B. S. and Lawrence, J. H. J. Lab. Clin. Med. 36 (1950) 40.

6. Hennessy, T. J. and Huff, R. L. Proc. Soc. Exptl. Biol. Med. 73 (1950) 436.

7. Loftfield, R. B. and Bonnichsen, R. Acta Chem. Scand. In press.

8. Theorell, H. and Åkeson, A. Ann. Acad. Sci. Fennicae, Ser. A II No. 60, p. 303.

9. Agner, K., Bonnichsen, R. and Hevesy, G. Scand. J. Clin. \& Lab. Invest. 6 (1954) 261.

10. Schuck, J. Arch. Gynäkol. 172 (1942) 52.

11. Ludewig, S. and Chanutin, A. Am. J. Physiol. 166 (1951) 384.

12. Elmlinger, P. J., Huff, R. L., Tobias, C. A. and Lawrence, J. Acta Haematol. 9 (1953) 73.

13. Haskins, D., Stevens, A. R. Jr., Finch, S. and Finch, C. A. J. Clin. Invest. 31 (1952) 542.

14. Sheppard, C. W. and Stewart, M. J. J. Cellular Comp. Physiol. 39, Suppl. 2 (1952) 189.

15. Nizet, A., Lambert, S., Herve, A. and Bacq, Z. M. Arch. intern. physiol. 52 (1954) 129.

Acta Chem. Scand. 9 (1955) No 3 
16. Brecher, G., Endicott, K. M., Gump, H. and Browner, H. P. Blood 3 (1948) 1259.

17. Lutwak-Mann, C. Biochem. J. (London) 49 (1951) 300.

18. Mandel, P., Metais, P., Gros, C. and Voegtlin, R. Compt. rend. 233 (1951) 1685.

19. Richmond, J. E., Altmen, K. I. and Salomon, K. J. Biol. Chem. 190 (1951) 817.

20. Stokinger, H. E., Altman, K. I. and Salomon, K. Biochim. et Biophys. Acta 12 (1953) 439.

21. Thomas, R. G., Altmen, K. I., Stannard, J. N. and Salomon, K. Radiation Research 1 (1954) 180.

22. Helwig, H. L. and Greenberg, D. M. J. Biol. Chem. 198 (1952) 703.

23. Knowlton, N. P. Jr. and Widner, W. R. Cancer Research 10 (1950) 59.

24. Nizet, A., Bacq, Z. M. and Herve, A. Arch. intern. physiol. 60 (1952) 449.

25. Tullis, J. L. Am. J. Pathol. 25 (1949) 829.

26. Strittmatter, C. F. and Ball, E. G. Proc. Natl. Acad. Sci. U. S. 38 (1952) 55.

27. Drabkin, D. L. J. Biol. Chem. 182 (1950) 317.

28. Theorell, H., Beznák, M., Bonnichsen, R., Paul, K. G. and Åkeson, A. Acta Chem. Scand. 5 (1951) 455.

29. Hahn, P. F., Bale, W. F. and Balfour, W. M. Amer. J. Physiol. 135 (1942) 600.

Received December 22, 1954. 